\title{
TELEHEALTH FORGING AHEAD: OVERCOMING BARRIERS IN LICENSURE TO IMPROVE ACCESS TO CARE FOR SERVICE MEMBERS
}

\author{
KATIE AMBrose STOUT, PT, DPT ${ }^{1}$, KRISTINA MARTINEZ, OTR/L² \\ ${ }^{1}$ NRMC Department of Telehealth, Ft. Meade, MD ${ }^{2}$, DVBIC, JaHVAh, TAMPa, Fl
}

\section{ABSTRACT}

The telehealth initiatives of the Department of Defense (DoD) and Veterans' Health Administration (VHA) continue to test the limits of technology to provide the best care to our service members, veterans and their families. The DoD and VHA have credentialing systems in place to allow clinical practice between facilities. New legislation in the form of the Servicemembers' Telemedicine and E-Health Portability (STEP) Act will potentially expand telehealth clinical services across state lines into the homes of our service members and veterans.

Keywords: Department of Defense (DoD), Veterans' Health Administration (VHA), Defense and Veterans Brain Injury Center (DVBIC), telepractice, traumatic brain injury

\section{INTRODUCTION}

As telehealth services expand nationwide, the Department of Defense (DoD), Veterans' Health Administration (VHA), and the Defense and Veterans Brain Injury Center (DVBIC) are working to keep pace. Through the telehealth initiatives of the DoD, VHA, and DVBIC Office of Telemedicine, the development and implementation of services have been rapidly growing. Two such services are described below, with both providing treatment for military members with a history of traumatic brain injury (TBI) or concussion. Through the support of these clinics, we are able to serve active duty service members, as well as veterans who require specialized care.

\section{TELE-TBI CLINIC}

The Army's Northern Regional Medical Command (NRMC), with clinician support from DVBIC, created a Tele-TBI Clinic to provide specialty support to remote and troop intensive sites. The Tele-TBI Clinic is comprised of an interdisciplinary team that includes occupational therapy, speech-language pathology, physical therapy, social work, psychology, neuropsychology, neurology, and psychiatry.

The NRMC Tele-TBI clinic's network with military medical commands allows clients across the northeast United States to receive specialty care closer to home, with improved access. This model is particularly beneficial in areas with both increased traffic congestion and service members residing in geographically distant locations, wherein a "simple" appointment typically requires an all-day commitment or even an overnight stay. The Tele-TBI clinic's network helps to bring care closer to the service members and their families, no matter their location.

\section{James A. Haley VA HOSPITAl (JAHVAH)}

The James A. Haley VA Hospital (JAHVAH) in Tampa, Florida is currently in the collaborative phase to determine protocols for future telerehabilitation programs. JAHVAH is one of four major polytrauma hospitals serving our active duty military members and veterans. DVBIC based its hub for telehealth services at the JAHVAH due to its ability to provide comprehensive care with state-of-the art equipment and research efforts. For our clients with $\mathrm{TBI}$ and concussion, we have programs set up within the hospital to address their needs and assist with reintegration into their units, the community, and the civilian work force. Due to the large number of clients seeking services, we hope to better transition and assist them via the use of clinical video telehealth, as well as mobile and web-based applications. 


\section{Credentialing Process}

In order to provide services within the DoD and the VHA systems, each provider must complete a credentialing and privileging appointment process. The validation process ensures that providers have the proper education and training to practice and provide care. This credentialing process recognizes licensure from all 50 US states, the District of Columbia, and US Territories. The DoD and VHA also have a credentials transfer process for ease of clinician transfer from facility to facility. The existing credentials transfer process also allows for telehealth services to occur from one medical facility to another, as long as the provider is credentialed in both locations (i.e., the provider and the client locations).(1) (2) As we attempt to reach clients closer to home, one challenge we face is that often their home is several hours from the nearest military treatment facility or veterans' hospital.

\section{SERVICEMEMBERS' TELEMEDICINE AND E- HEALTh PORTABility (STEP) ACT}

The Servicemembers' Telemedicine and E-Health Portability (STEP) Act was drafted and approved by Congress in May, 2011, and is currently awaiting approval from the Committee on Armed Services and the Committee on Veterans Affairs. The original verbiage of the STEP Act is comprised of a mere 387 words which "authorizes the Secretary of Defense (DoD) to allow certain licensed health-care professionals to provide care to members of the Armed Forces at any location and regardless of where the professional of client is located, so long as the practice is within the scope of authorized federal duties."(3)

The final language for the STEP Act has not yet been determined. However, we hope that the final version will allow providers to see service members in their homes via telehealth technology, using the home as an extension of the military facility. This would greatly increase access to specialty care for our service members, decrease family burden, and increase family involvement in the service member's recovery process.

From our understanding, the STEP Act represents progress toward true inter-state practice, specifically for the treatment of military personnel without the licensure barrier. The STEP act could allow for improved access to care to a large population of service members who may not be close to specialty care and demonstrate the need for an improved system, country wide. Furthermore, the DoD's Telehealth credentialing model is a "hub and spoke" model which could be duplicated by state licensure boards.

\section{CONCLUSION}

While tele-practitioners throughout the United States face the challenges of inter-state licensure barriers, the DoD and VHA, in collaboration with DVBIC, continue to forge ahead with the creation of new telehealth services. Their mission is to serve our military members and veterans, first and foremost, through the most comprehensive of services. 


\section{REFERENCES:}

1. Army Regulation 40-68. Retrieved: www.apd.army.mil/ pdffiles/r40_68.pdf

2. VHA Handbook 1100.19: Credentialing and Privileging. Retrieved: www.va.gov/vhapublications/ViewPublication. asp?pub_ID=1806

3. H.R. 1832: STEP ACT. Retrieved: http://www. opencongress.org/bill/112-h1832/show

DISCLAIMER:

The views expressed in this article are those solely of the authors and do not express the views of the Department of the Army, Department of Defense, Department of Veterans Affairs or the U.S. Government. 
